\title{
Massimo PAZZINI, Lessico concordanziale del Nuovo Testamento Siriaco, Jerusalem 2004, Franciscan Printing Press, ss. 469.
}

Può considerarsi senz'altro una pietra miliare tra gli strumenti scientifici degli studi biblici e non solo, come avremo modo di considerare. Il Lessico concordanziale del Nuovo Testamento Siriaco (LCNTS) esce finalmente alle stampe dopo tempo di meticoloso lavoro scaturito dall'esperienza, altamente qualificata nelle competenze delle lingue semitiche ed orientali, di Padre Massimo Pazzini e motivato dall'istanza didattica, come egli stesso afferma: „Si tratta di pagine nate dalla scuola e pensate per la scuola, costruite sul corpus dell'intero NT".

Licenziato in teologia dogmatica e, quindi, in Teologia biblica, in possesso del BA in Lingua ebraica e Lingue semitiche antiche all'Università ebraica di Gerusalemme e laureato in Lingue e civiltà orientali all'Istituto Universitario Orientale di Napoli, l'Autore, Frate Minore della Provincia dell'Emilia Romagna, è professore di ebraico, aramaico e siriaco presso lo Studium Biblicum Franciscanum, Facoltà di Scienze bibliche e Archeologia, di Gerusalemme e già ha insegnato come docente invitato all'École Biblique di Gerusalemme: un'esperienza culturale ed accademica, dunque, la sua, ad ampio orizzonte di confronto, rigore e specialità, e che lo ha portato a maturare, dopo la pubblicazione della Grammatica Siriaca e di due testi di analisi del libro di Rut, l'uno ebraico e l'altro siriaco, questa notevole opera. Essa contiene tutte le forme presenti nel Nuovo Testamento, unitamente ad una peculiarità: „Tali forme, spiega l'Autore, sono pienamente vocalizzate, compresa l'indicazione di ruk$k \bar{o} k h \bar{o}$ e quššoyō". Sarà utile pertanto non solo a chi svolgerà una ricerca di tipo lessicale, bensì pure grammaticale. E questa novità, oltre quella di offrire il carattere fonologico e morfologico, specialmente per le forme verbali, rende il LCNTS utilissimo all'ipotesi di impiego anche in campo patristico.

I Padri orientali costituiscono ancora un campo di studio aperto, in particolare per l'acquisizione filologica delle loro opere originali, mediazione scientifico-letteraria basilare per la più corretta e profonda ermeneutica del loro pensiero teologico. L'uso e l'impasto di testi e citazioni della Sacra Scrittura con il linguaggio dei Padri della Chiesa si sa quanto abbia inciso sulle loro opere e quanto ne abbia intriso il messaggio. Dal NT siriaco ai Padri orientali l'esplorazione è una sfida che, se per il settore patristico greco e latino si è avvalsa di strumenti e di studi sofisticati e qualificati, non altrettanto può ancora dirsi per le altre aree linguistiche di comprensibile maggiore difficoltà di accesso ai patrologi. Il LCNTS di Padre Pazzini si colloca pertanto come strumento di arrivo e di stimolo per l'avvio di nuove indagini nell'importante settore della Patristica orientale.

Nell'Introduzione l'Autore presenta, oltre un'essenziale bibliografia di dizionari e glossari di siriaco dei quali si è avvalso per consultazioni, una guida 
all'uso del Lessico per quanto concerne i sostantivi, gli oggettivi, i verbi, le varianti ed i nomi propri, chiarificando con esempi l'esposizione, e segnala quelle caratteristiche specifiche del criterio seguito nella compilazione delle voci non verbali e verbali. Va sottolineato che la peculiarità in assoluto inedita è quella concordanziale: oltre la traduzione italiana, di ogni termine è offerto l'eventuale rimando alla parola greca, aramaica biblica od ebraica biblica corrispondente, valenza anche questa non indifferente ad un'eventuale applicazione patristica di raffronto tra testi di Patrologia orientale e testi di Patrologia greca o versioni greche della prima, onde ricostruire importanti filoni ermeneutici nella transizione semantica della loro tradizione cristiana.

Fatica non indifferente nella complessità della stesura è quindi pure questa, che accanto alla lodevole competenza professionale di Padre Pazzini vede affiancarsi la passione scientificamente rigorosa dell'amante della Scrittura, in quale in Prefazione dichiara: „Non disponendo di un testo siriaco in formato digitalizzato, lo abbiamo scritto parola per parola e ciò ci ha aiutati a cogliere le sfumature semantiche di ogni singolo lemma".

Siamo pertanto dinanzi ad un'opera il cui alto valore non è attribuibile soltanto alla mente dello studioso, bensì pure in armoniosa intelligenza anche con la sua anima, uscitane stupita di „voce" in „voce" da una sorta di scoperta di „lectio divina" che nell'ultima riga del testo fa tracciare in siriaco all'umile Autore di tanto elevato lavoro: "E' terminato questo scritto, a Dio sia la gloria che non ha fine. AMEN AMEN".

Luciana Maria Mirri - Bologna

\section{Bogdan CZYŻEWSKI, Księgi Pisma Świętego w ujęciu isagogi Juniliusza Afrykańczyka, Poznań 2003, Wydawnictwo Naukowe UAM, ss. 318.}

„Jest to niewielkie pismo zawierające teorię biblijnej egzegezy, które można nazwać wprowadzeniem do studiowania i poznania Pisma Świętego" - tak ks. Bogdan Czyżewski charakteryzuje traktat Juniliusza Afrykańczyka, biskupa nieznanej diecezji w Afryce w VI wieku, zatytułowany Instituta regularia divinae legis (w rozprawie pismo to jest najczęściej cytowane jako isagoga, czyli wprowadzenie do studiów biblijnych). Ten niewielki traktat okazuje się ważny i ciekawy, chociaż mało znany. W polskiej literaturze naukowej nie doczekał się dotąd zadnych większych opracowań poza notkami w słownikach czy podręcznikach patrologii. Rozprawa B. Czyżewskiego stanowi więc pierwszą tego rodzaju rozprawę.

Książka omawia fundamentalne kwestie nauczania biblijnego, jakie porusza tekst isagogi: problem kanonu, hermeneutyki i teologii biblijnej, itd. By ukazać jednak oryginalność myśli i ujęć Juniliusza, ks. Czyżewski przedstawia poruszane przez niego zagadnienia w szerszej perspektywie historycznej, bib- 